\title{
Обработка металлов и диэлектриков аргоновой СвЧ-плазмой атмосферного давления
}

\author{
С. Шиляев ${ }^{1}$, С. Постнов ${ }^{2}$
}

УДК 533.9.07| ВАК 05.27.06

Качество подготовки поверхности перед адгезионным соединением определяет его прочность, а также долговечность конечного изделия. К настоящему времени большое распространение в обработке материалов получили методы плазменной обработки, использующие вакуумные камеры и установки плазменного барьерного разряда. Применение СВЧ-плазмы атмосферного давления имеет много преимуществ по сравнению с этими методами, а также с традиционными жидкостными методами подготовки поверхности материалов. Для атмосферной аргоновой СВЧ-плазмы не требуется вакуумная камера, плазму можно генерировать при небольших мощностях, и она имеет большой выход продуктов плазмохимии, поскольку аргоновая плазма атмосферного давления допускает работу как в чисто аргоновой атмосфере, так и в потоке аргона с подмешиванием воздуха, водяных паров и другого необходимого сопутствующего газа (например, кислород, азот, водород и т.д.). В данной статье рассматриваются результаты обработки различных материалов аргоновой СВЧ-плазмой, которые были получены на оборудовании ООО «Руднев-Шиляев".

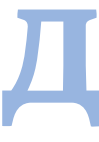
ля исследования влияния атмосферной СВЧ-плазмы на поверхность материалов применялось несколько методов: гониометрический метод, метод определения поверхностного натяжения калиброванными жидкостями, исследование морфологии поверхности при помощи атомно-силового микроскопа, метод электронной микроскопии. Объектами исследования служили материалы, указанные в табл. 1.

Поверхности металлов и диэлектриков обрабатывались на установке атмосферной аргоновой СВЧ-плазмы, в которой предусмотрены манипулятор и перемещающийся стол с возможностью выбора скорости перемещения (рис. 1). Гранулы материалов обрабатывались в плазменной установке проточного типа с реактором, изолированным от внешней среды, где осуществлялось движение материала через плазменный поток.

В ходе работ были выбраны оптимальные режимы для обработки поверхностей металлов и диэлектриков, а также гранул.

Ниже представлены данные, полученные после обработки в оптимальных режимах. На рис. 2 приведены значения равновесного краевого угла смачивания у обработанных и необработанных поверхностей металлов. На

ООО «Руднев-Шиляев», генеральный директор, sereg@rudshel.ru. О०О «Руднев-Шиляев», научный сотрудник, adc@rudshel.ru. рис. 3 и рис. 4 показаны, соответственно, значения равновесного краевого угла смачивания и поверхностного натяжения у обработанных и необработанных поверхностей диэлектриков.

Примеры результатов исследования на атомносиловом микроскопе морфологии поверхностей необработанной и обработанной полиимидной пленки представлены на рис. 5 и 6 соответственно.

Обработанные в плазменной установке проточного типа и необработанные образцы гранул диаметром 50-150 мкм спекали при высокой температуре. После

Таблица 1. Материалы, подвергнутые обработке СВЧ-плазмой

\begin{tabular}{|c|c|c|}
\hline \multicolumn{3}{|c|}{ Материалы } \\
\hline \multicolumn{2}{|c|}{ Металлы } & Диэлектрики \\
\hline Поверхности & Гранулы & Поверхности \\
\hline $\begin{array}{c}\text { Вольфрам, } \\
\text { молибден, } \\
\text { дюраль д16Т, } \\
\text { сталь 3, } \\
\text { медь }\end{array}$ & $\begin{array}{c}\text { Интер- } \\
\text { металлиды }\end{array}$ & $\begin{array}{c}\text { Фторопласт, } \\
\text { полиимид, } \\
\text { поликор, } \\
\text { ситалл, } \\
\text { свч-керамика, } \\
\text { диоксид } \\
\text { кремния }\end{array}$ \\
\hline
\end{tabular}



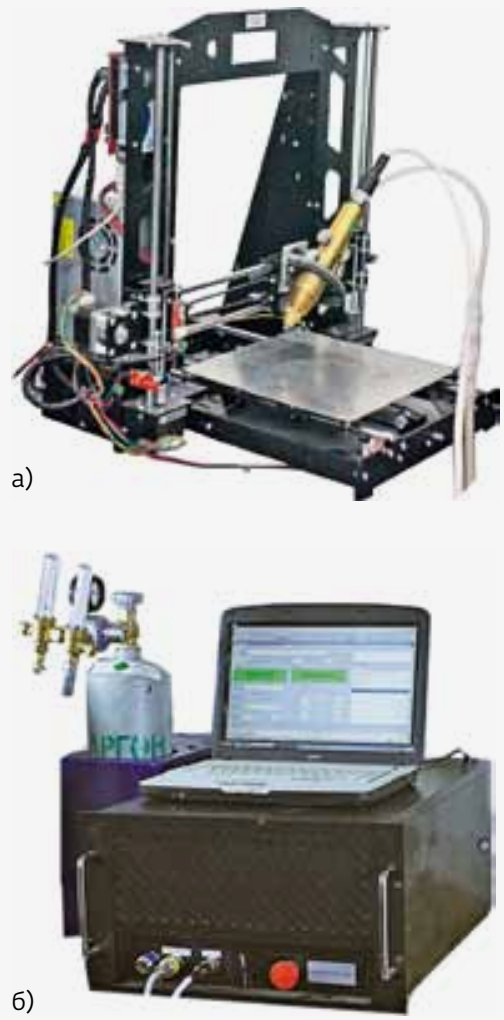

Значение равновесного краевого угла смачивания,

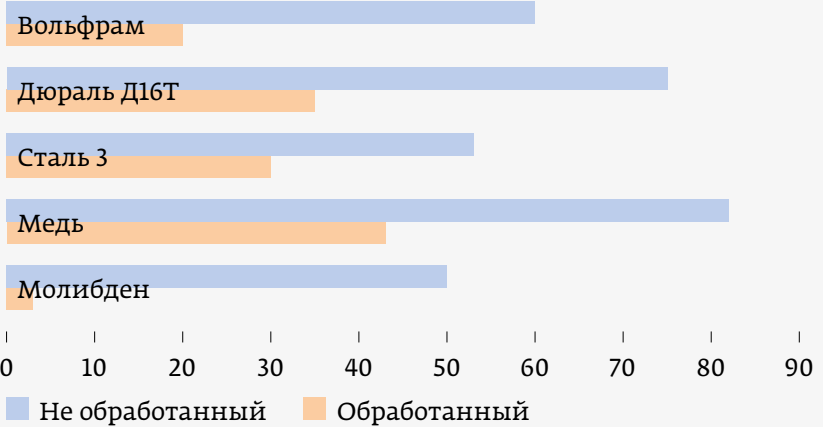

Рис. 2. Значения равновесного краевого угла смачивания у обработанных и необработанных поверхностей металлов
Рис. 1.

Установка

для получе-

ния аргоновой

СВЧ-плазмы:

а - манипулятор, б - генератор этого полученные материалы исследовались на электронном микроскопе методом обратно отраженных электронов. Как видно из рис. 7 и 8, при одинаковой температуре и времени выдержки удалось добиться лучшего спекания гранул после воздействия СВЧ-плазмой.

Были также обнаружены явные различия в содержании кислорода в областях ореолов, формирующихся вокруг гранул при спекании. Темные области на поверхности (см. рис. 7 и 8) означают наличие кислородных соединений. Видна разница между образцами с обработанными и необработанными гранулами и тенденция к уменьшению в результате обработки количества кислорода на поверхности в местах спекания гранул. Отсутствие на поверхности кислородных соединений уменьшает риски разрушения образцов.

Еще одно возможное применение аргоновой СвЧ-плазмы - сфероидизация металлов. Проблема создания сложных форм готовых изделий из тугоплавких материалов заключается в нетекучести материала исходной формы и его непластичности. Используя подобранные режимы плазменной установки проточного типа, мы смогли достичь сфероидизации исходного материала (рис. 9). Удалось получить в результате сфероидизации гранулы размером 20-60 мкм в количестве до 90\% от исходного материала. Альтернативных способов сфероидизации тугоплавких интерметаллидов нет.
Значение равновесного краевого угла смачивания,

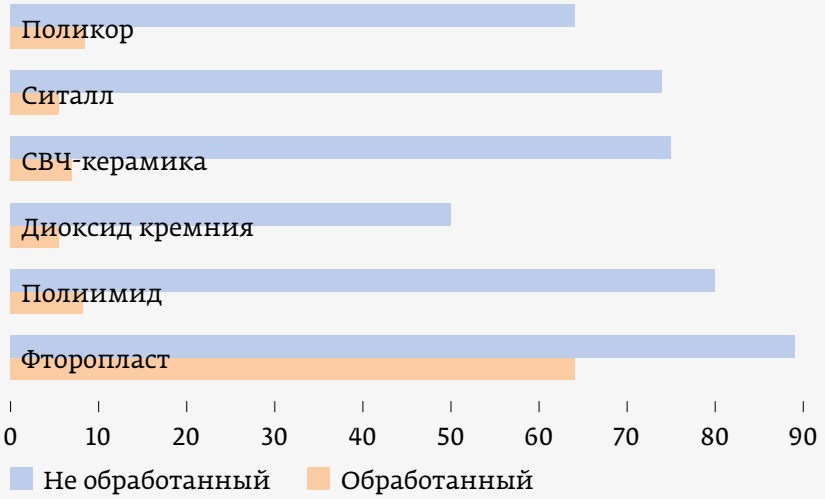

Рис. 3. Значения равновесного краевого угла смачивания у обработанных и необработанных поверхностей диэлектриков

Значение поверхностного натяжения, мН / м

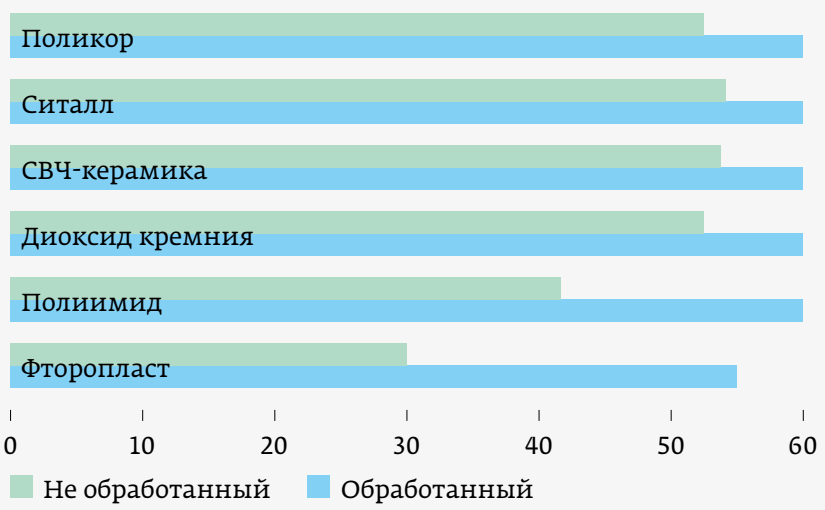

Рис. 4. Значения поверхностного натяжения у обработанных и необработанных поверхностей диэлектриков 


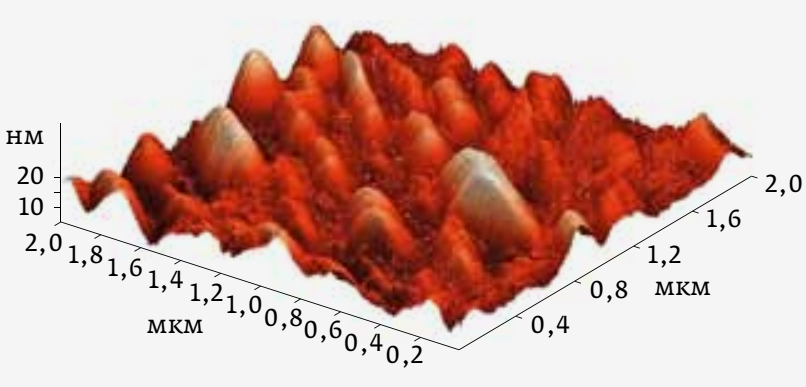

Рис. 5. Морфология поверхности необработанной полиимидной пленки

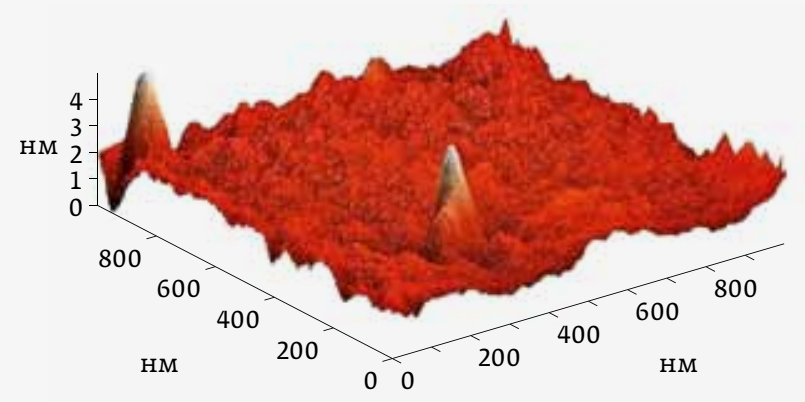

Рис. 6. Морфология поверхности обработанной полиимидной пленки

Рассмотрим также влияние плазменной обработки на диэлектрические параметры керамической шихты. Обрабатывая несколько различных образцов шихты в разных режимах, нам удалось добиться изменения по всем диэлектрическим параметрам. Тангенс угла потерь образца шихты № 1 при стандартной температуре $20^{\circ} \mathrm{C}$ слабо изменяется в результате обработки; при увеличении температуры до $100^{\circ} \mathrm{C}$ видно, что тангенс угла потерь у обработанного образца остается практически неизменным во всем диапазоне частот, а у необработанного - увеличивается на порядок с уменьшением частоты (рис. 10). Для образца № 2 мы добились стабилизации параметров в области низких частот: от 0,5 Гц до 100 кГц (рис. 11).

Отметим, что при наклеивании на поверхность полиимида датчиков возможны проблемы с адгезией. Эту задачу необходимо решать, не создавая анизотропию при активации поверхности. Обработку Свч-плазмой можно использовать для подготовки поверхности с изменяемой геометрией. Данный способ не вносит анизотропию в обрабатываемую поверхность.

Таким образом, проведенные исследования показывают эффективность применения СВЧ-плазмы атмосферного давления для обработки поверхностей перед созданием адгезионных соединений, а также для обработки

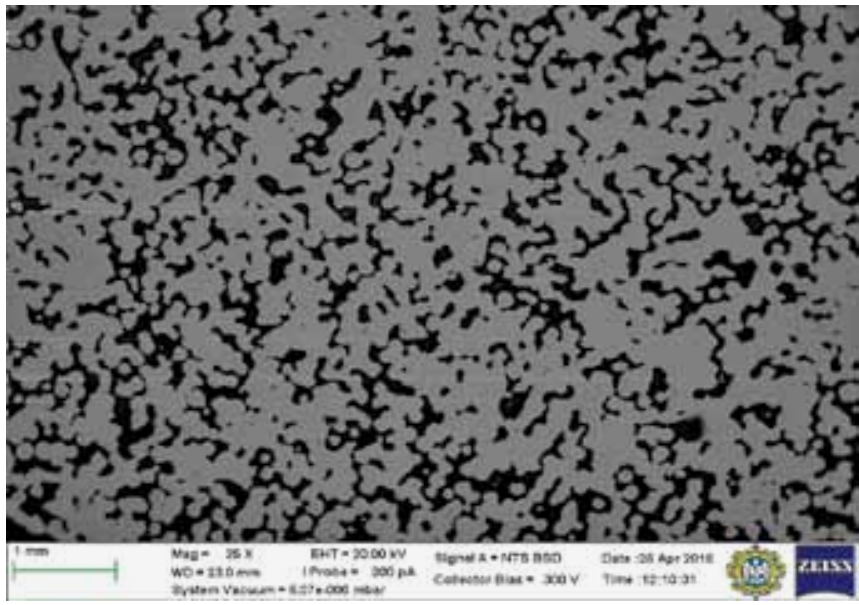

Рис. 7. Не обработанные в плазме гранулы, подвергнутые термической обработке

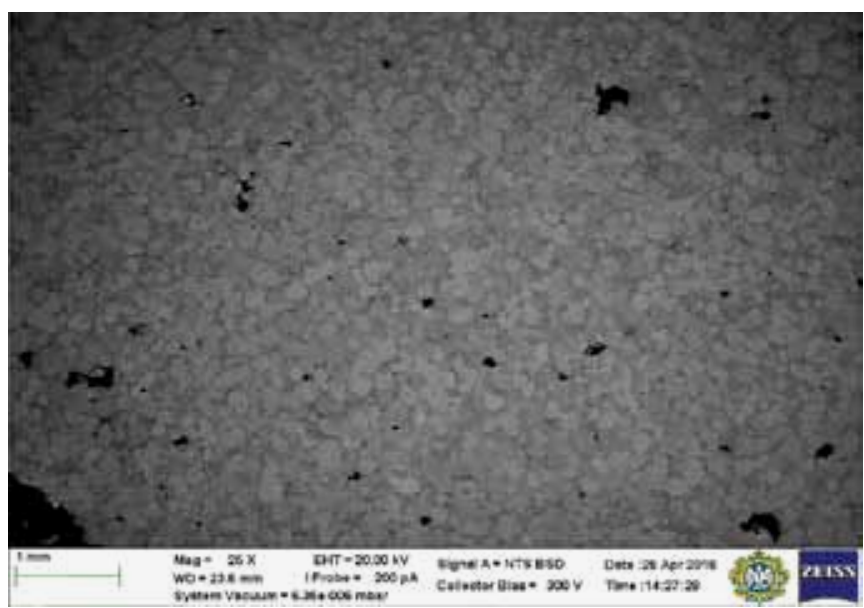

Рис. 8. Обработанные в плазме гранулы, подвергнутые термической обработке

Исходный материал

Полученный материал ( $\varnothing 20-60$ мКм)
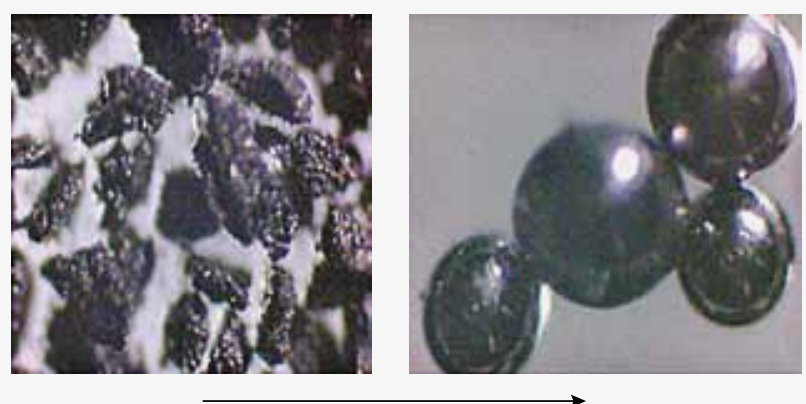

Воздействие плазмы

Рис. 9. Сфероидизация металлов 

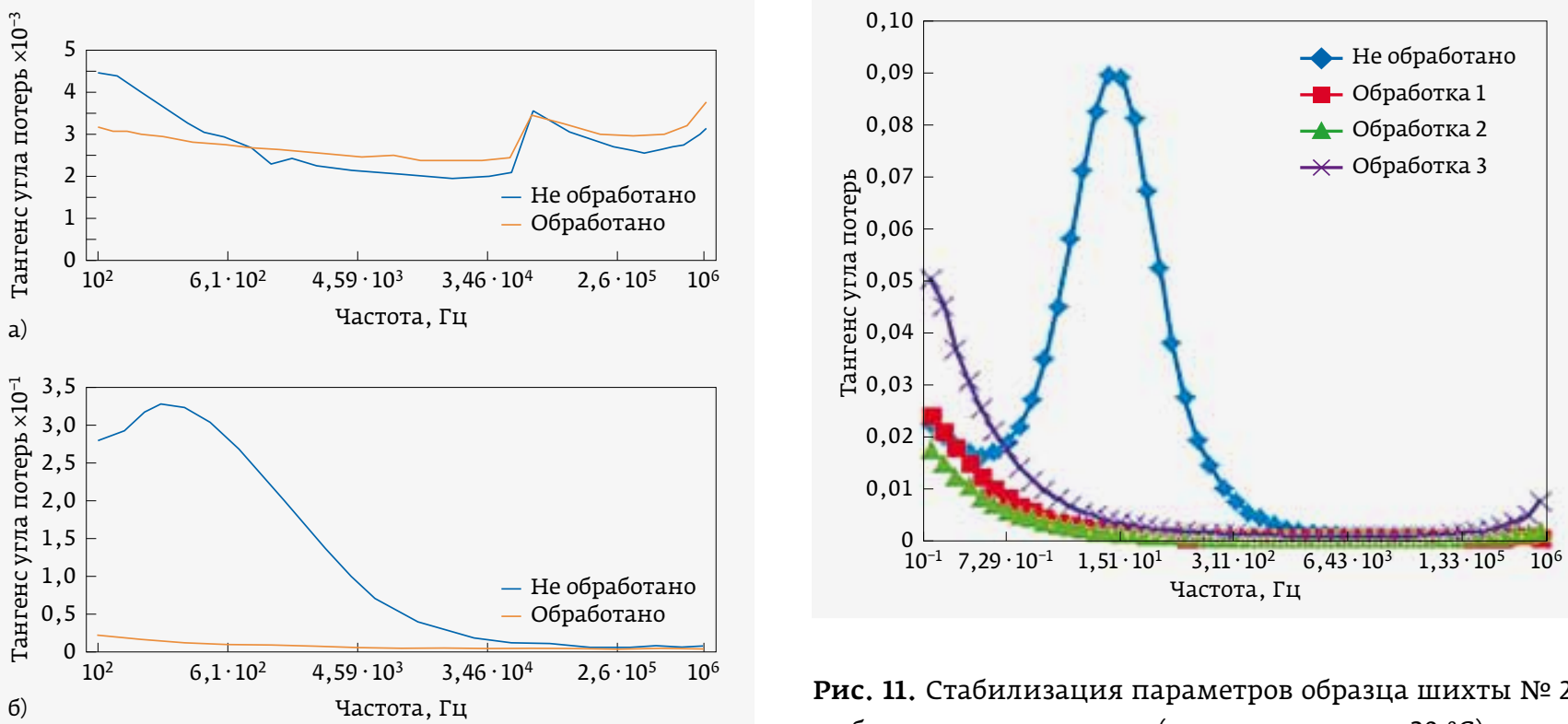

Рис. 11. Стабилизация параметров образца шихты № 2 в области низких частот (при температуре $20^{\circ} \mathrm{C}$ )

Рис. 10. Тангенсы угла потерь обработанного и необработанного образцов шихты № 1 при температуре $20^{\circ} \mathrm{C}$ (а) и $100{ }^{\circ} \mathrm{C}$ (б)

образцов перед спеканием в порошковой металлургии. Использование такой плазмы для обработки металлов

и диэлектриков позволяет повысить технологичность изготовления конечных изделий.

Более подробную информацию можно найти на сайте О०० «Руднев-Шиляев»: www.rudshel.ru.

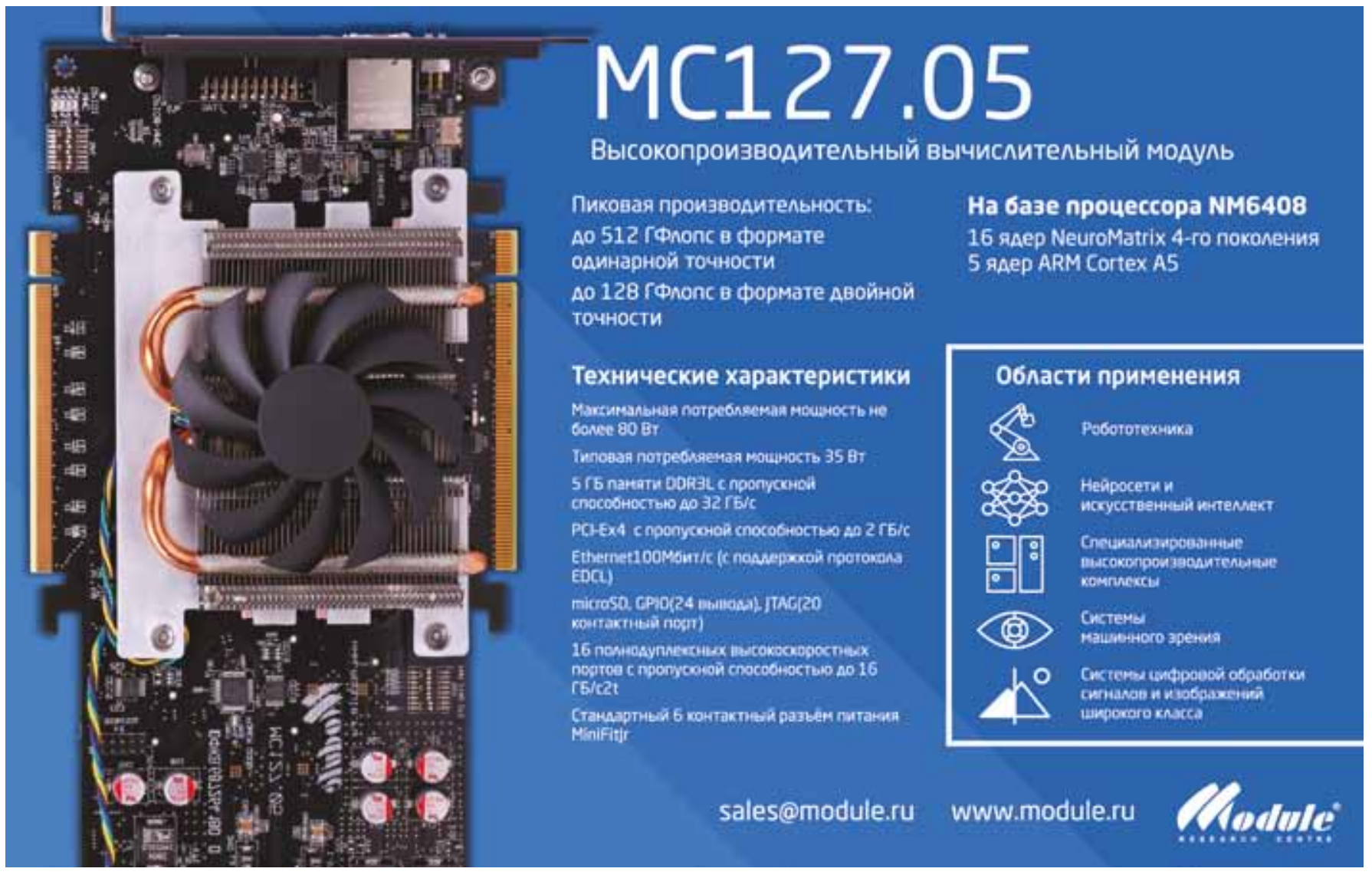

